UHERO

THE ECONOMIC RESEARCH ORGANIZATION AT THE UNIVERSITY OF HAWAI'I

\section{JOINT MANAGEMENT OF AN INTERCONNECTED COASTAL AQUIFER AND INVASIVE TREE}

BY

SITTIDAJ PONGKIJVORASIN, KIMBERLY BURNETT, AND CHRISTOPHER WADA

Working Paper No. 2017-8

October 5, 2017 


\title{
Joint Management of an Interconnected Coastal Aquifer and Invasive Tree
}

\author{
Sittidaj Pongkijvorasin, ${ }^{a}$ Kimberly Burnett, ${ }^{b, *}$ Christopher Wada ${ }^{b}$ \\ ${ }^{a}$ Faculty of Economics, Chulalongkorn University, Phayathai Road, Bangkok 10330, Thailand. \\ ${ }^{b}$ University of Hawai'i Economic Research Organization, 2424 Maile Way, Saunders Hall 540, \\ Honolulu, HI 96822, USA. \\ Corresponding author
}

\begin{abstract}
Kiawe (Prosopis pallida), a mesquite tree considered invasive in many parts of the world including Hawai' $i$, has been shown to reduce regional groundwater levels via deep taproots. In areas where aquifers are primary sources of fresh water, kiawe control has the potential to be an integral component of water management planning. We develop an analytical dynamic framework for the joint management of kiawe and groundwater, and show that optimal water management depends on expected kiawe damages, while optimal kiawe removal depends on groundwater scarcity and removal cost. Using data from the Kinholo aquifer on the west coast of Hawai' $i$ Island, we solve for joint management decisions with corresponding parameters related to kiawe damage and water scarcity. With $1.5 \%$ water demand growth, Kiawe should be removed if the removal cost is below $\$ 1,884 /$ ha. Our numerical results indicate that kiawe damage is nonlinear in the rate of water demand growth. The damage costs can be attributed to three main factors. When demand growth is low, kiawe damage is driven by a higher water extraction cost. For moderate growth, the effect is compounded by anticipated future scarcity. Damage is amplified by a backstop cost effect when the growth rate is high.
\end{abstract}

Keywords: Prosopis pallida, kiawe, groundwater management, invasive species, Kīholo 


\title{
Joint Management of an Interconnected Coastal Aquifer and Invasive Tree
}

\begin{abstract}
Kiawe (Prosopis pallida), a mesquite tree considered invasive in many parts of the world including Hawai' $i$, has been shown to reduce regional groundwater levels via deep taproots. In areas where aquifers are primary sources of fresh water, kiawe control has the potential to be an integral component of water management planning. We develop an analytical dynamic framework for the joint management of kiawe and groundwater, and show that optimal water management depends on expected kiawe damages, while optimal kiawe removal depends on groundwater scarcity and removal cost. Using data from the Kinholo aquifer on the west coast of Hawai' $i$ Island, we solve for joint management decisions with corresponding parameters related to kiawe damage and water scarcity. With $1.5 \%$ water demand growth, Kiawe should be removed if the removal cost is below $\$ 1,884 /$ ha. Our numerical results indicate that kiawe damage is nonlinear in the rate of water demand growth. The damage costs can be attributed to three main factors. When demand growth is low, kiawe damage is driven by a higher water extraction cost. For moderate growth, the effect is compounded by anticipated future scarcity. Damage is amplified by a backstop cost effect when the growth rate is high.
\end{abstract}

Keywords: Prosopis pallida, kiawe, groundwater management, invasive species, Kīholo

\section{Introduction}

Kiawe (Prosopis pallida) is a nonnative tree introduced to Hawai' $\mathrm{i}$ in the early nineteenth century that can potentially reduce coastal groundwater quality by providing nitrogen-rich organic material for leaching, as well as reduce regional groundwater levels via deep taproots (Richmond and Mueller-Dombois, 1972, Dudley et al. 2014). Kiawe can be found in both coastal wetlands and upland ecosystems, covering over 60,000 ha of the state's total land area (Gon et al. 2006). The introduction of kiawe into leeward coastal areas of Hawai'i Island has been shown to increase groundwater uptake, altering local hydrological processes including possible reductions in submarine groundwater discharge (Dudley et al. 2014).

The objective of this paper is to help extend the principles of resource economics to deal with the joint management of interdependent resources, and provide an illustrative case from Hawai' $i$, where the groundwater uptake of an invasive species detracts from the aquifer stock. Building off of a simple model developed in Burnett et al. (2014), we employ a standard approach of maximizing the present value (PV) of net benefits generated by the groundwater aquifer, and specify the optimal steady state stock level of both stock of water and invasive species, while characterizing the path of optimal resource management leading to those steady states. The difference in NPV's between the case with and without management is one approach to characterizing damages from the invasive species (or alternatively, the benefits of invasive species management).

Prosopis pallida was introduced from South America to areas in Asia, Africa, and Oceania during the early nineteenth century. The first kiawe in Hawai' $i$ was planted in 1828 on the island of O‘ahu (Wilcox 1910, Birkett 2007). By the 1890s, kiawe was widely recognized for its use as 
cattle feed and fuel wood. Consequently, kiawe spread rapidly throughout the dry leeward lowland areas of $\mathrm{O}^{\prime}$ ahu and the other main islands of Hawai' $i$, its spread directly linked to its use as feed for the growing cattle industry in Hawai'i.

A characteristic of kiawe's invasive nature is its rapid growth, described as reaching full height of 6-8m within three or four years (Hall 1904). The tree reaches maximum height and productivity in riparian zones with access to shallow groundwater (Schade et al. 2003). Kiawe are described as phreatophytes ("groundwater-loving plants"), referring to their root system, which is capable of accessing relatively deep groundwater sources. This deep taproot system has been implicated in lowering groundwater tables in Hawai'i (Richmond and Mueller-Dombois 1972). On Kaho'olawe, Stearns (1940) found that a decline in the groundwater level coincided with the spread of kiawe. Zones (1961) speculated that kiawe transpiration was responsible for an observed daily rise and fall of the groundwater level on $\mathrm{O}^{`}$ ahu (Pasiecznik et al. 2001). Large stands of kiawe remain on all the main islands of Hawai' $i$, particularly where development is limited and cattle ranching continues.

Decision rules for the economically efficient allocation of groundwater were first developed almost half a century ago (Burt, 1967; Brown and Deacon, 1972). More recent efforts have refined the hydrogeological aspects of the management framework, developed instruments for implementing optimal extraction, and considered the welfare implications of various management strategies (Krulce et al., 1997; Koundouri 2004; Brozović et al., 2010). Few, however, have considered the simultaneous management of natural resources that are interconnected with the aquifer of interest. Those that have modeled resource interdependency (both within and outside the groundwater literature) typically focused on management of a single resource, taking harvest from the adjacent resource as exogenous, e.g., shrimp farms and offshore fisheries (Barbier et al., 2002) and groundwater and nearshore species such as seaweed (Duarte et al., 2010).

Efficient joint management of water and invasive species will recognize linkages between these resources (Burnett et al. 2007, Funk et al. 2014). Managing invasive species can have direct or indirect benefits on environmental outcomes such as water quality (Connelly et al. 2007), air quality (Jones et al. 2006), and landscape flammability (Wada et al. 2017). There are several examples of invasive species with well-measured effects on linked water resources (Turpie et al. 2008, Van Wilgen 2001). An example of a plant invader with well-studied implications to water is salt cedar (Tamarix spp.), which is found in floodplains throughout in the southwestern United States and consumes 3000-4600 cubic meters per hectare per year more water than does the native vegetation that it replaces (Zavaleta 2000). Another plant species, yellow starthistle (Centaurea solstitialis), results in water losses due to its late summer drawdown of soil moisture amounting to as much as $\$ 75$ million each year in the economically important agricultural region surrounding the Sacramento River (Gerlach 2004). In the model presented here, management decisions consider direct tradeoffs both between resources (groundwater and kiawe) and over time. In an application near Kîholo Bay on the island of Hawai'i, a basic groundwater management model was modified to include water uptake by kiawe.

Our study site is located along the Kona coast near Kîholo Bay on Hawai'i Island. Kiawe's long taproots extend into the ground through cracks in the rock. Kinholo Bay receives considerable 
shallow submarine groundwater discharge near its shoreline via freshwater flow from the upper watershed (Peterson et al., 2009). Dudley et al. (2014) documented kiawe's access to groundwater along this coast and found that kiawe stands were able to successfully access and utilize groundwater and subsequently transpire substantially $(\sim 80 \%)$ more water than was supplied via rainfall. Results support the idea that the presence of kiawe has altered the hydrological processes of this region, which is now characterized by a negative water budget through groundwater uptake and continuous transpiration. We use this data to parameterize an illustrative joint management model of groundwater and kiawe, where the stock of groundwater provides benefit, and the stock of kiawe affects this benefit directly via groundwater uptake through its taproots.

\section{Materials and Methods}

\subsection{Aquifer dynamics}

We assume a single-cell coastal aquifer (Figure 1), where the head level $(h)$, or the distance between mean sea level and the top of the freshwater lens, is proportional to the volume of stored groundwater; $\gamma$ is a volume-height conversion factor. The head level changes over time according to recharge $(R)$, natural leakage along the aquifer boundary $(L)$, extraction $(q)$, and uptake $(u)$ by overlying kiawe trees $(K)$ as shown in equation (1):

$$
\dot{h}_{t}=\gamma\left[R-L\left(h_{t}\right)-q_{t}-u\left(K_{t}\right)\right]
$$

Recharge $(R)$, or the quantity of freshwater that replenishes the aquifer annually, is taken as exogenous and constant in our model, but more generally depends on factors such as precipitation patterns, characteristics of adjacent water bodies, and the types of land cover overlying the recharge zone. Leakage is an increasing and convex function of head (i.e., $L^{\prime}\left(h_{t}\right)>0$ and $\left.L^{\prime \prime}\left(h_{t}\right) \leq 0\right)$. A higher head level generates greater pressure along the aquifer boundary, ultimately resulting in more leakage at the coast in the form of submarine groundwater discharge and/or springs. 


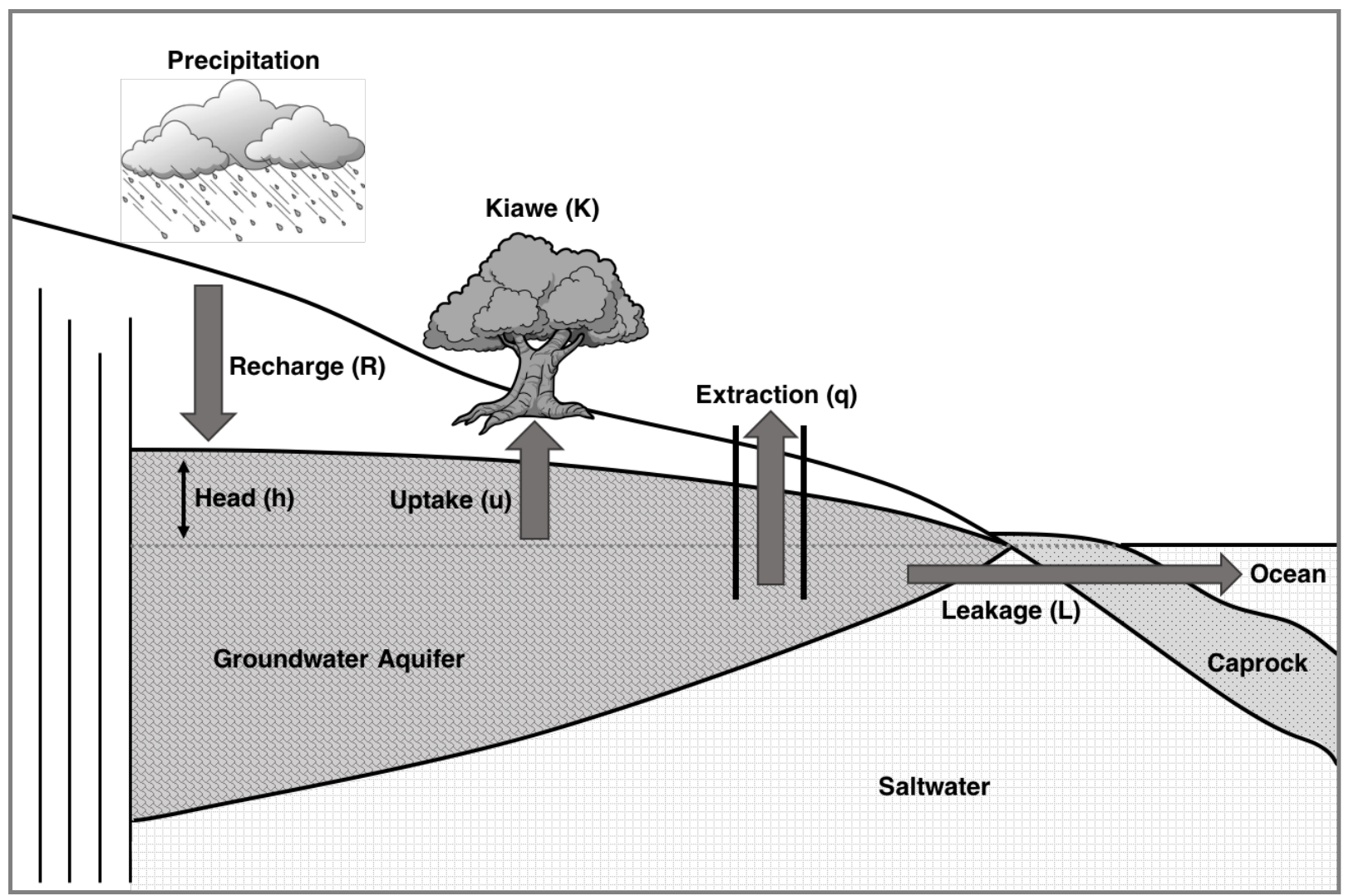

Figure 1: Coastal aquifer cross-section

\subsection{Kiawe dynamics}

Kiawe spreads according to the stock-dependent net-growth function $F$. We assume that the growth represents the spread of kiawe over space, and in the application the stock $(K)$ is measured in units of area (e.g., hectares). Kiawe can also be removed or exterminated at rate $x$. Thus, the change in kiawe stock in any period is determined jointly by its natural growth rate and management effort (equation 2).

$$
\dot{K}_{t}=F\left(K_{t}\right)-x_{t}
$$

\subsection{Benefits}

The benefit of water use is measured as the area under the inverse demand curve $\left(D^{-1}\right)$ as shown in equation (3):

(3) $\quad B_{t}=\int_{0}^{q_{t}+b_{t}} D^{-1}\left(y_{t}, t\right) d y$ 
A backstop resource $(b)$, desalination, can be used to supplement or replace groundwater extraction. We assume that the sources are indistinguishable in terms of quality and therefore have the potential to generate identical marginal benefits at a given level of consumption. The inverse demand is also directly a function of $t$ to allow for the possibility that demand for water is rising over time due to population and/or per capita income growth.

\subsection{Costs}

The cost of groundwater extraction is a decreasing and convex function of the head level $c_{q}(h)$. The more depleted the aquifer, the more energy is required to lift groundwater over a longer distance to the ground surface. We assume that desalinated brackish water can be obtained at a constant unit $\operatorname{cost} c_{b}$.

The unit cost of tree removal $\left(c_{\mathrm{x}}\right)$ is assumed to be constant and is comprised of chemical, mechanical and/or labor costs. We assume that once a tree is removed, no additional maintenance is required. The total cost of obtaining water and managing kiawe in period-t is shown in equation (4):

$$
C_{t}=c_{q}\left(h_{t}\right) q_{t}+c_{b} b_{t}+c_{x} x_{t}
$$

\subsection{Optimization problem}

The dynamic optimization problem faced by the resource manager is to choose groundwater extraction, desalination, and kiawe removal in every period to maximize the present value (PV) of net benefits (equation 5), i.e.

$$
\max _{q_{t}, b_{t}, x_{t}} \int_{0}^{\infty} e^{-r t}\left[B_{t}-C_{t}\right] d t
$$

subject to equations (1) and (2), as well as non-negativity constraints on the control variables and head level. The discount rate $(r)$ is positive, and the initial head level $\left(h_{0}\right)$ and kiawe stock level $\left(K_{0}\right)$ are known. The corresponding current value Hamiltonian is shown in equation (6):

$$
H=B_{t}-C_{t}+\gamma \lambda_{t}\left[R-L\left(h_{t}\right)-q_{t}-u\left(K_{t}\right)\right]+\mu_{t}\left[F\left(K_{t}\right)-x_{t}\right]
$$

where $\lambda$ is the co-state variable or shadow price of the groundwater stock and $\mu$ is the co-state variable or shadow price of the kiawe stock.

\footnotetext{
${ }^{1}$ The assumption that the planner can perfectly substitute between the aquifer and desalination is meant to keep the model analytically tractable but could be viewed as overly simplistic from a practical standpoint; a desalination purchase contract is often required for a set period, which would result in a horizontal or stepped (rather than smoothly inclining) production trajectory once desalination comes online. The problem of optimal desalination expansion (e.g. Saif and Almansoori, 2014) is itself, i.e. without being coupled with invasive species management, complex. Although outside the scope of the current study, the ideal joint management model would incorporate a suite of possible groundwater substitutes including desalination (Roumasset and Wada, 2010; Beh et al., 2014), and the management problem would entail optimizing both the use of groundwater and the order of supply side alternatives, while accounting for invasive species interactions.
} 
The Maximum Principle requires that the following necessary conditions (equations 7-13) hold (Chiang, 2000):

$$
\begin{array}{ll}
\boldsymbol{\partial H} / \boldsymbol{\partial} \boldsymbol{q}_{\boldsymbol{t}}=\boldsymbol{D}^{-\mathbf{1}}\left(\boldsymbol{q}_{\boldsymbol{t}}+\boldsymbol{b}_{\boldsymbol{t}}, \boldsymbol{t}\right)-\boldsymbol{c}_{\boldsymbol{q}}\left(\boldsymbol{h}_{\boldsymbol{t}}\right)-\boldsymbol{\gamma} \boldsymbol{\lambda}_{\boldsymbol{t}} \leq \mathbf{0}, & \text { if }<\text { then } \boldsymbol{q}_{\boldsymbol{t}}=\mathbf{0} \\
\partial H / \partial b_{t}=D^{-1}\left(q_{t}+b_{t}, t\right)-c_{b} \leq 0, & \text { if }<\text { then } b_{t}=0 \\
\partial H / \partial x_{t}=-c_{x}-\mu_{t} \leq 0, & \text { if }<\text { then } x_{t}=0 \\
\dot{\lambda}_{t}-r \lambda_{t}=-\partial H / \partial h_{t}=c_{q}{ }^{\prime}\left(h_{t}\right) q_{t}+\gamma \lambda_{t} L^{\prime}\left(h_{t}\right) & \\
\dot{\mu}_{t}-r \mu_{t}=-\partial H / \partial K_{t}=\gamma \lambda_{t} u^{\prime}\left(K_{t}\right)-\mu_{t} F^{\prime}\left(K_{t}\right) & \\
\dot{h}_{t}=\partial H / \partial \lambda_{t}=\gamma\left[R-L\left(h_{t}\right)-q_{t}-u\left(K_{t}\right)\right] & \\
\dot{K}_{t}=\partial H / \partial \mu_{t}=F\left(K_{t}\right)-x_{t} &
\end{array}
$$

\subsection{Efficiency price for water}

The efficiency price is defined as the price that would incentivize the optimal rate of water extraction and consumption generated by the solution to equation (5). Taking the time derivative of $\lambda$ in (7) results in $\gamma \dot{\lambda}_{t}=\dot{p}_{t}-c^{\prime}\left(h_{t}\right) \dot{h}_{t}$, where $p_{t} \equiv D^{-1}\left(q_{t}+b_{t}, t\right)$. The following equation can then be derived by plugging that result and (7) into (10):

$$
p_{t}=c\left(h_{t}\right)+\frac{\dot{p}_{t}-\gamma c\left(h_{t}\right)\left[R-L\left(h_{t}\right)-u\left(K_{t}\right)\right]}{r+\gamma L L^{\prime}\left(h_{t}\right)}
$$

The right-hand side of equation (14) is the marginal opportunity cost (MOC) of groundwater extraction and includes two terms: the marginal extraction cost and marginal user cost (MUC) of water. At the optimum, the marginal benefit of water $(p)$ must be equal to the MOC. Otherwise, an incremental increase or decrease in pumping could raise total PV net benefit. Interpretation of the marginal extraction cost is straightforward, but the MUC requires some explanation. The MUC represents the PV cost associated with the decision to pump a unit of water today, rather than wait. It includes effects on future prices, future changes in extraction costs, and future changes in leakage. The impact of kiawe is captured in the numerator; a higher stock of $K$, all else equal, reduces the head level and therefore amplifies the extraction cost effect.

\subsection{Optimal kiawe removal}

An optimality condition, analogous to the efficiency price condition for water, can be derived for kiawe by taking the time derivative of (9) and substituting the result into (11):

$$
c_{x}=\frac{\gamma \lambda_{t} u \prime\left(K_{t}\right)}{r-F^{\prime}\left(K_{t}\right)}
$$


Equation (15) says that the marginal cost of keeping water in the ground via kiawe removal should be equal to the marginal benefit of that water. From (7) and (14), we can see that $\lambda$ is the MUC along the optimal path. Thus, the right-hand side of (15), is the value of the change in uptake generated by a marginal increase in $x$, adjusted for the discount rate and the growth effect.

Since the Hamiltonian (6) is linear in kiawe removal $(x)$, management should follow a most rapid approach path (MRAP) to the steady state. The optimal removal rule is to choose the maximum feasible number of trees to remove in every period whenever the left-hand side (LHS) < righthand side (RHS) in (15), until the optimal long-run level of $K$ is reached, at which point $x^{*}=$ $F\left(K^{*}\right)$. If instead LHS $>$ RHS in (15), the manager should allow kiawe to grow until $K^{*}$ is reached, at which point $x$ must be chosen to maintain $K^{*}$.

Generally, optimal deferment of kiawe removal is more likely when $c_{\mathrm{x}}$ is high, $\lambda$ is low (groundwater is relatively abundant), the uptake rate is low, the discount rate is high, and/or the kiawe growth rate is low.

\subsection{Optimal internal steady state}

An optimal internal steady state solution is one in which the backstop resource is never used. For any candidate steady state solution, all state variables must remain constant. The optimal steady state head level $\left(h^{*}\right)$, if it exists, must therefore satisfy $b=0, \dot{p}=0, \dot{h}=0, \dot{K}=0$, and

$$
p^{*}=c\left(h^{*}\right)-\frac{\gamma c^{\prime}\left(h^{*}\right)\left[R-L\left(h^{*}\right)-u\left(K^{*}\right)\right]}{r+\gamma L^{\prime}\left(h^{*}\right)}
$$

It is straightforward to confirm that the partial derivative of the RHS of equation (16) with respect to $h^{*}$ is unambiguously negative. Thus, the steady-state head level that solves (16) is unique. If the candidate $\mathrm{MOC}^{*}$ is less than the cost of desalination, then $\mathrm{h}^{*}$ is unique and optimal. If instead the MOC at the candidate internal steady state is greater than $c_{b}$, then the unrestricted steady state is not optimal, and desalination should be used in the steady state to supplement pumping.

\subsection{Optimal backstop steady state}

If it is determined that the internal steady state solution corresponding to (16) is not optimal, then the long-run solution includes desalination. The optimal backstop steady state head level $\left(h_{b}^{*}\right)$ must satisfy $p=c_{b}, \dot{p}=0, \dot{h}=0, \dot{K}=0$, and

$$
c_{b}=c\left(h_{b}^{*}\right)-\frac{\gamma c \prime\left(h_{b}^{*}\right)\left[R-L\left(h_{b}^{*}\right)-u\left(K_{b}^{*}\right)\right]}{r+\gamma L \prime\left(h_{b}^{*}\right)}
$$

One can show that the partial derivative of the RHS of equation (17) with respect to $h_{b}^{*}$ is unambiguously negative, ensuring that the solution is unique. Moreover, since $p^{*}>c_{b}$, it must be true that $h^{*}<h_{b}^{*}$, which implies that $h_{b}^{*}$ is not only unique but also positive. In summary, if $p^{*}<c_{b}$ then the $h^{*}$ in (16) is the optimal internal steady state solution. If not, then the $h_{b}^{*}$ in (17) is the optimal backstop steady state solution. 


\section{Application}

We use the hydrological parameters and equations from Pongkijvorasin et al. (2010), Duarte (2002), and Mink (1980) to characterize the groundwater resource. Our study site, the Kinholo aquifer, is a thin basal groundwater lens located on the North Kona coast of Hawai' $i$ Island. We assume a sharp freshwater-saltwater interface because the high porosity in Kinholo renders the brackish transition zone relatively thin. The equation of motion for the head level can be expressed as $\dot{h_{t}}=\left(\frac{2000}{41 \theta W L}\right)\left(R-L\left(h_{t}\right)-q_{t}\right)$, where $\theta$ is porosity (the ratio of pore space available for the transmission of fluids to the total volume of rock), $W$ is aquifer width, and $L$ is aquifer length. For the Kinholo aquifer, porosity is $0.3, W$ is $6,000 \mathrm{~m}$, and $L$ is $6,850 \mathrm{~m}$, which implies that the volume-height conversion factor $\gamma=\frac{2000}{41 \theta W L}=0.00000396$. The structural expression for leakage or discharge is $L\left(h_{t}\right)=z h_{t}^{2}$, with $z=4,800$ in for the Kinholo aquifer. Recharge is assumed constant at $15,114 \mathrm{tm}^{3} /$ year. The cost of pumping groundwater is driven primarily by the cost of energy required to lift the water to ground level. The unit cost of water extraction as a function of lift for the Kinholo aquifer is $c\left(h_{t}\right)=0.001\left(403.2-h_{t}\right)$, and the unit cost of desalination, including amortized capital costs, is estimated at $\$ 2.00 / \mathrm{m}^{3}$. We use a linear demand function of the form $p_{t}=3.98-0.006 q_{t}$, where the coefficients were determined using the retail price in the region and an assumed price elasticity of -0.7 .

Kiawe growth is assumed to follow a logistic growth function of the form $g K_{t}\left(1-K_{t} / \beta\right)$, where $g$ is the intrinsic growth rate and $\beta$ is the carrying capacity (Conrad, 2012). The former varies from $2.5 \%$ to $7.5 \%$ in our sensitivity analysis, with $5 \%$ representing the baseline case. The latter was estimated to be roughly $400 \mathrm{ha}$, using satellite imagery of the region. Although the rate of kiawe growth is not very well understood and varies by location, existing studies suggest that Prosopis can spread at rates ranging from 3.5-30\% (Shackleton et al., 2015; Wise et al., 2012). Miyazawa et al. (2015) estimated that annual transpiration of kiawe in the Kinolo region is roughly $84 \%$ higher than rainfall, and that imbalance is attributed to groundwater uptake. Annual rainfall at the study site during the period of data collection was $188 \mathrm{~mm}$, which translates to approximately $1.6 \mathrm{tm}^{3} / \mathrm{ha} /$ year. The baseline value for uptake is $1.6 \mathrm{tm}^{3} / \mathrm{ha} /$ year, and we allow it to vary from 0.4 to $2.8 \mathrm{tm}^{3} /$ ha/year, which is $\pm 75 \%$ of the baseline case, in the sensitivity analysis. Other studies outside of Hawai' $i$ have estimated uptake rates ranging from 0.03 to 0.66 $\mathrm{tm}^{3} /$ ha/year (Dzikiti et al., 2013; Le Maitre et al., 2015; Wise et al., 2012).

Table 1: Parameter descriptions and baseline values used in the simulation of Kīholo aquifer

\begin{tabular}{|l|l|l|}
\hline Parameter & Description [units] & Value \\
\hline$\gamma$ & Volume-height conversion factor & 0.00000396 \\
\hline$R$ & Recharge $\left[\mathrm{tm}^{3} / \mathrm{y}\right]$ & 15114 \\
\hline$h_{0}$ & Initial head level $[\mathrm{m}]$ & 1.75 \\
\hline$h_{g r d}$ & Ground elevation $[\mathrm{m}]$ & 403.2 \\
\hline$E C$ & Energy cost of lifting $1 \mathrm{~m}^{3}$ up $1 \mathrm{~m}\left[\$ / \mathrm{m} / \mathrm{m}^{3}\right]$ & 0.001 \\
\hline$c_{b}$ & Desalination cost $\left[\$ / \mathrm{m}^{3}\right]$ & 2 \\
\hline$z$ & Leakage coefficient & 4800 \\
\hline$a$ & Water demand intercept & 3.98 \\
\hline
\end{tabular}




\begin{tabular}{|l|l|l|}
\hline$b$ & Water demand coefficient & 0.0006 \\
\hline$K_{0}$ & Initial kiawe stock [ha] & 100 \\
\hline$v$ & Kiawe water uptake rate $\left[\mathrm{tm}^{3} / \mathrm{ha} /\right.$ day $]$ & 1.6 \\
\hline$\beta$ & Kiawe carrying capacity $[\mathrm{ha}]$ & 400 \\
\hline$g$ & Kiawe intrinsic growth rate [\%] & 5 \\
\hline$r$ & Discount rate [\%] & 3 \\
\hline
\end{tabular}

Table 2: Equations used in the simulation of Kiholo aquifer

\begin{tabular}{|l|l|}
\hline Function & Equation \\
\hline Aquifer state & $\dot{h}_{t}=\gamma\left[\alpha\left(K_{t}\right) R-L\left(h_{t}\right)-q_{t}\right]$ \\
\hline Leakage & $L\left(h_{t}\right)=z h_{t}^{2}$ \\
\hline Unit groundwater extraction cost & $c\left(h_{t}\right)=E C\left(h_{g r d}-h_{t}\right)$ \\
\hline Inverse demand for water & $p_{t}=a-b q_{t}$ \\
\hline Kiawe water uptake & $u\left(K_{t}\right)=v K_{t}$ \\
\hline Kiawe growth & $\dot{K}_{t}=g K_{t}\left(1-K_{t} / \beta\right)$ \\
\hline
\end{tabular}

\section{Results}

Assuming a constant unit cost of kiawe removal, optimal kiawe management will follow a most rapid approach path to the steady state (recall that the Hamiltonian is a linear function in removal). In other words, the optimal decision will be to either remove all the kiawe if the damage is greater than the removal cost or to remove none of the kiawe if the damage is less than the removal cost. Kiawe damage is calculated for each scenario as the difference in net present value (NPV) of water use with and without kiawe present. Damage depends largely on the scarcity of water, which in turn is determined by 1) water demand and 2) water consumed by kiawe. Thus, we explore the sensitivity of the results with respect to the growth rate of water demand, the kiawe uptake rate, and the intrinsic growth rate of kiawe. We begin by solving for the optimal paths and NPV of optimal water management under the assumption that no kiawe is present. Then, the optimal paths and NPV of joint water and kiawe management are calculated. The optimal management of kiawe is determined by comparing the damage costs with removal costs.

\subsection{Optimal water management without kiawe}

We begin by solving for optimal water management without kiawe for different growth rates of water demand (Figure 2). In general, water use is growing while head level is declining over time. For higher growth rates of water demand, total water use grows at a faster rate, and the head level is drawn down more rapidly as expected. Taking a slightly more nuanced approach, we divide the results into three groups, according to the growth rate of water demand. 


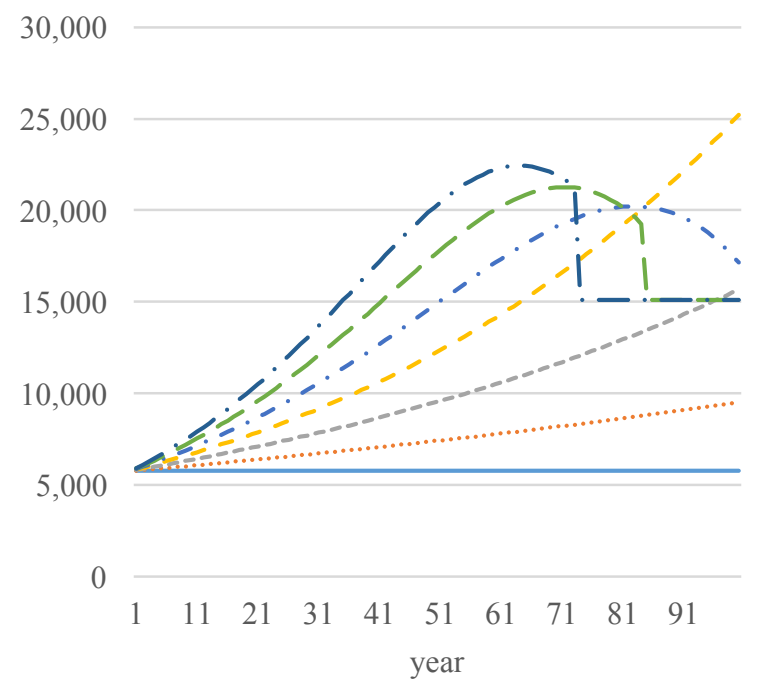

(a) Groundwater extraction $\left(\mathrm{tm}^{3} / \mathrm{y}\right)$

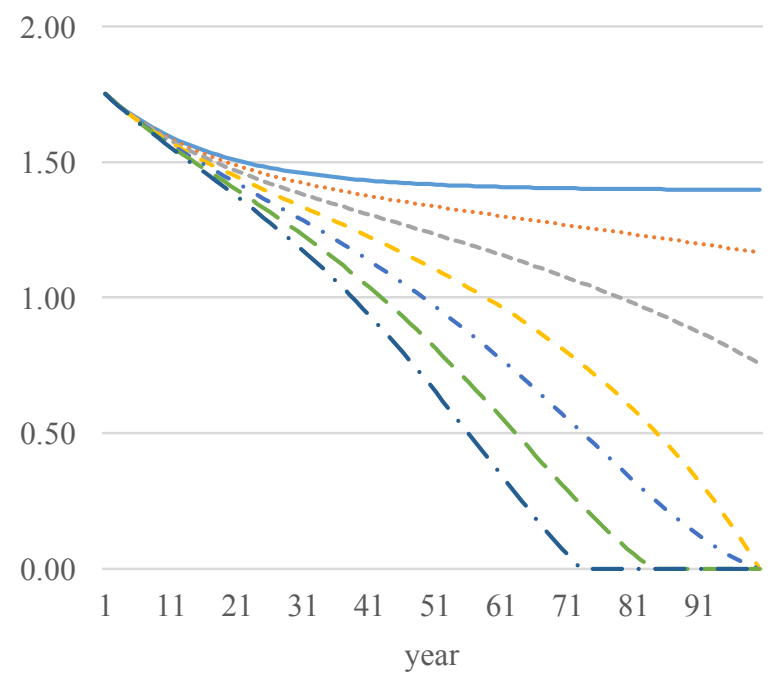

(c) Head level of aquifer (m)

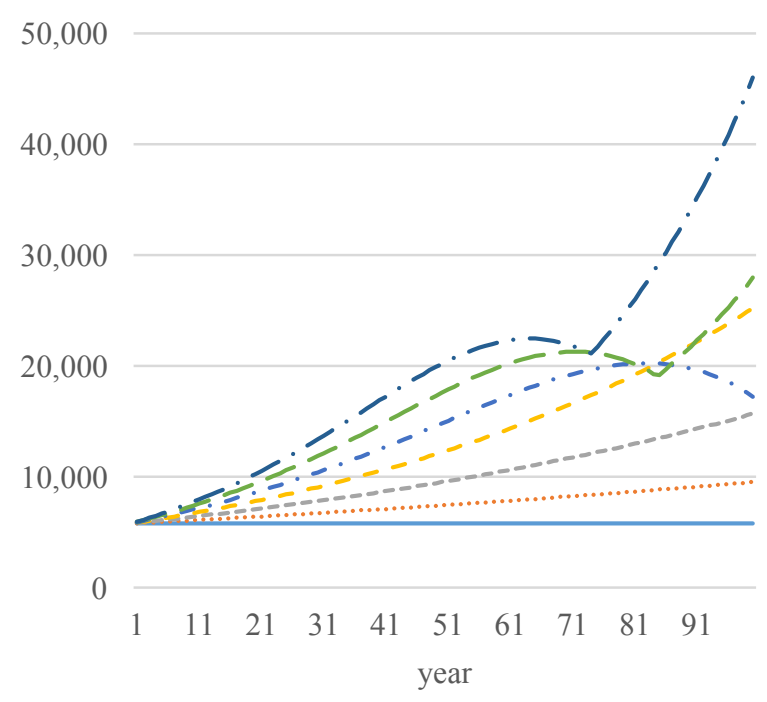

(b) Total water use $\left(\mathrm{tm}^{3} / \mathrm{y}\right)$

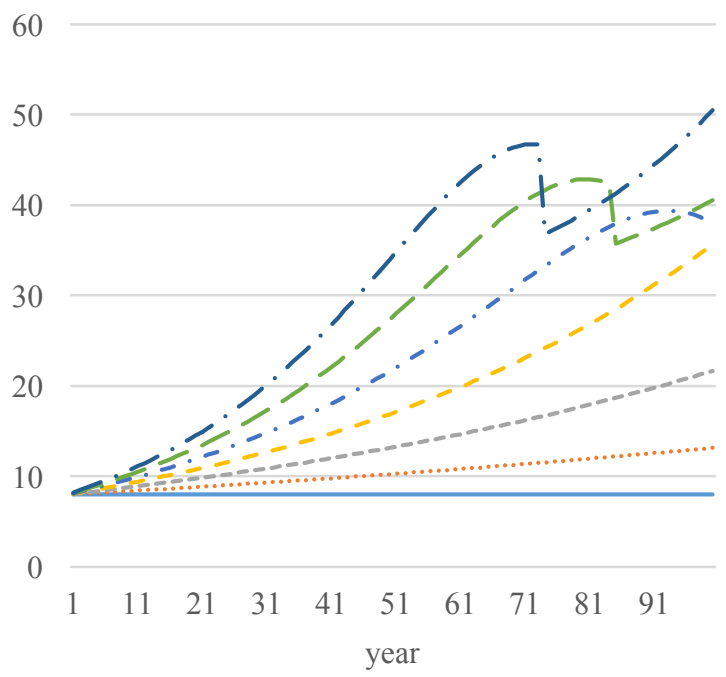

(d) Net benefit (million \$)

$0 \%$

$0.50 \%$ $1 \%$ $-1.50 \%$

$-\cdot-2 \%$

$--2.50 \%-\cdot-3 \%$

Figure 2: Optimal paths of variables for the case of no kiawe with different growth rate of water demand.

\subsubsection{Zero or low growth rate of water demand}

When the growth rate of water demand is less than $\sim 1.5 \%$, groundwater extraction increases at the same rate as water demand (Figure 2a), leaving the efficiency price of water constant. The 
head level decreases slowly over time but remains positive at the end of the planning horizon (year 100), which implies that groundwater is still available (Figure 2c). The backstop resource, desalination, is never introduced. Net benefits from water use grow at the same rate as water demand (Figure 2d).

\subsubsection{Moderate growth rate of water demand}

When the growth rate of water demand falls in the range of $1.5-2 \%$, the groundwater head level optimally reaches approximately zero at year 100 (Figure 2c). In the beginning, optimal groundwater extraction grows at the same rate as water demand. However, as we approach the end of the planning horizon, the rate of optimal extraction falls, due to the impending scarcity of groundwater (Figure 2a). The backstop resource is still avoided in this case. The net benefit from water use grows apace with water demand initially but falls behind in later years (Figure 2d).

\subsubsection{High growth rate of water demand}

When the growth rate of water demand exceeds $2 \%$, groundwater is depleted before year 100 , thus requiring desalination as a supplementary resource (Figure 2c). For example, if water demand grows at $2.5 \%$ or $3 \%$ annually, then the backstop is optimally introduced in year 84 and 74 respectively. Like in the moderate growth rate case, extraction grows at the same rate as water demand initially but slows as groundwater is depleted. Once desalination is introduced, groundwater extraction is limited to recharge and any demand exceeding extraction is met by the backstop resource. Thus, total water use grows at the same rate as water demand once desalination comes online (Figure 2b). Net benefit from water use grows at the same rate as water demand initially, grows more slowly in intermediate years, drops sharply at the introduction of desalination, and then returns to the growth rate of water demand near the end of planning period (Figure 2d).

\subsection{Optimal water management with kiawe}

In the presence of kiawe, less water will be available for consumption due to uptake. Overall, groundwater extraction, head level, and net benefit from water use will be lower than in the case of no kiawe (Figure 3).

\subsubsection{Zero or low growth rate of water demand}

With zero or low water demand growth, groundwater is still available after 100 years, and the optimal path of groundwater extraction is only slightly lower than the no kiawe case (Figure 3a). This results in a lower optimal head level path (Figure 3c) and NPV from water use (Figure 3d). Desalination is never used. When demand is constant, for example, the presence of kiawe lowers optimal groundwater extraction by less than $1 \mathrm{tm}^{3} /$ year (Figure 3a), and the head level at year 100 is $1.35 \mathrm{~m}$, compared to $1.40 \mathrm{~m}$ without kiawe (Figure 3c). The corresponding damage cost of kiawe is estimated at $\$ 2,427$ for the entire area or $\$ 24.27 /$ ha over 100 years, which means that all the kiawe should be removed in the initial period only if removal cost is less than $\$ 24.27 /$ ha. If instead the removal cost is higher than $\$ 24.27 /$ ha, optimal kiawe management entails no removal initially. (Kiawe damage per hectare will sometimes be referred to as the "critical removal cost" 
hereafter.) When the growth rate of demand is $1 \%$, the critical removal cost increases to $\$ 44.45 /$ ha (Table 3). When demand growth is low, kiawe damage is due entirely to future increases in groundwater extraction cost as the head level declines.

\subsubsection{Moderate growth rate of water demand}

With moderate demand growth, optimal groundwater extraction is lower than the no kiawe case (Figure 3a). The difference starts small but grows over time as water becomes scarcer. Along the optimal path, the head level is lower than the no kiawe case (Figure 3c). Like the extraction rate, net benefit from water use with kiawe is lower than the case without kiawe (Figure 3d). The backstop resource, desalination, is never used. As a specific example, when the growth rate of water demand is $1.5 \%$, the optimal groundwater extraction rate is about $1 \mathrm{tm}^{3}$ lower than optimal extraction without kiawe in the first year (Figure 3a). By year 100, that difference grows to 1,550 $\mathrm{tm}^{3}$. The head level with kiawe is lower everywhere along the optimal path, but in both cases, the head level reaches 0 at year 100 (Figure 3d) and the backstop is never used. The damage from kiawe is negligible in the first year, but it increases to more than $\$ 230,000$ for the entire area in year 100 in current value terms. The present value damage of kiawe is estimated to be $\$ 188,379$ for the entire area over 100 years, implying a critical removal cost of $\$ 1,884 /$ ha (Table 3 ). When demand growth is moderate, kiawe damage is driven by two factors: 1) the higher cost of future groundwater extraction due to the head level effect and 2) limited water supply, which puts downward pressure on optimal extraction in later years.

\subsubsection{High growth rate of water demand}

When the growth rate of water demand is high, the head level is completely drawn down within 100 years (Figure 3c). Before the backstop is optimally introduced, the general pattern of optimal extraction and net benefit is the same as the moderate growth case. After the introduction of desalination (when the head level reaches $0 \mathrm{~m}$ ), groundwater extraction is limited to recharge, net of kiawe uptake. Although total water use is the same whether kiawe is present or not (Figure $3 b$ ), the difference in net benefit after the backstop introduction stems from the relatively high cost of desalination (Figure 3d). For example, if the growth rate of demand is $3 \%$, the backstop is optimally introduced in year 73, one year earlier than the no kiawe case. The difference in groundwater extraction increases from 0 to almost $700 \mathrm{tm}^{3}$ in 72 years (Figure 3a). Once the backstop is introduced, the difference is equal to kiawe uptake, or approximately $700 \mathrm{tm}^{3} /$ year. The damage cost of kiawe is estimated at $\$ 5,859,970$ for the entire area over 100 years, which corresponds to a critical removal cost of $\$ 58,600 /$ ha (Table 3 ). When demand growth is high, kiawe damage is explained by three factors: 1) the higher cost of future groundwater extraction due to the head level effect, 2) the need to save water before the head level is drawn down, and 3 ) the high cost of the backstop technology relative to groundwater extraction. 


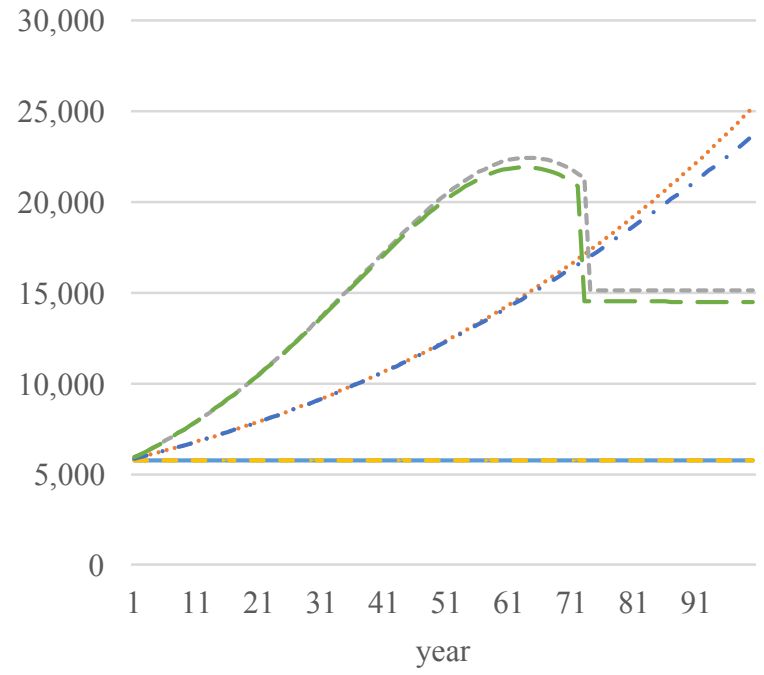

(a) Groundwater extraction $\left(\mathrm{tm}^{3} / \mathrm{y}\right)$

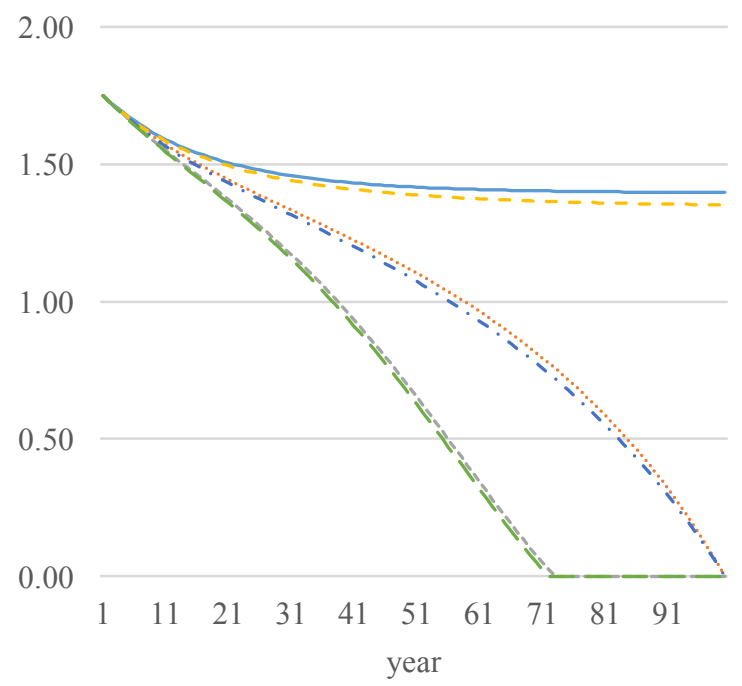

(c) Head level of aquifer (m)

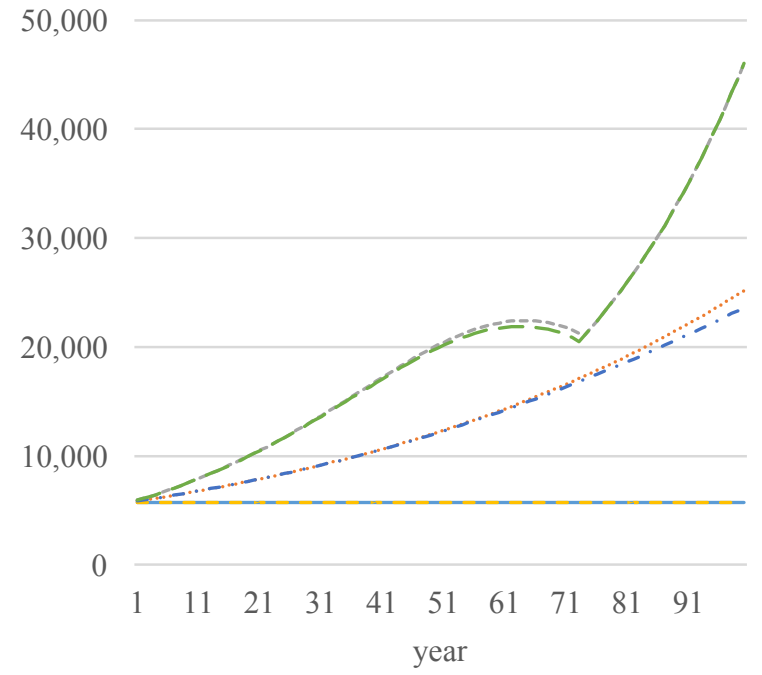

(b) Total water use $\left(\mathrm{tm}^{3} / \mathrm{y}\right)$

60

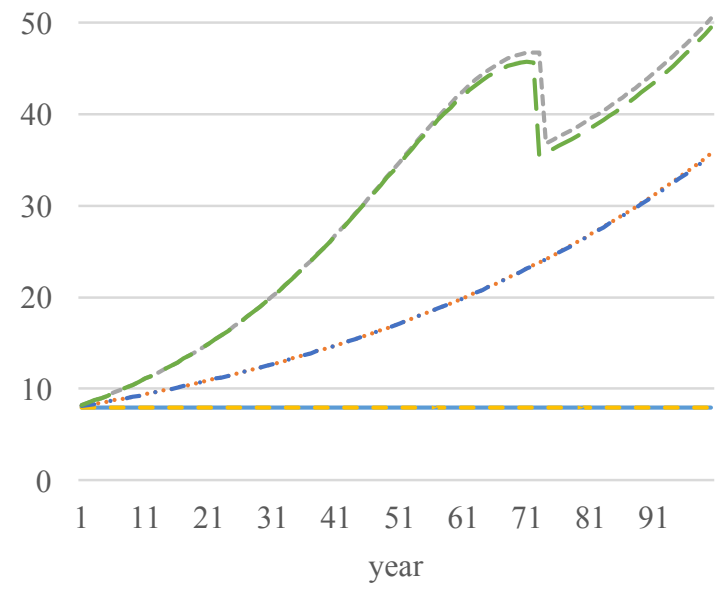

(d) Net benefit (million \$)

$$
\begin{gathered}
-0 \% \text { no Kiawe } \quad \cdots . . .1 .5 \% \text { no Kiawe }----3 \% \text { no Kiawe } \\
---0 \% \text { with Kiawe } \quad-\cdot-1.5 \% \text { with Kiawe }--3 \% \text { with Kiawe }
\end{gathered}
$$

Figure 3: Optimal paths of variables with and without kiawe for demand growth rates of 0 , 1.5, and 3 percent.

Using the optimal paths illustrated in Figure 3, we estimate kiawe damage costs (Table $3)$. As the rate of water demand growth increases, water scarcity increases, and the damage of kiawe is higher. Interestingly, the damage of kiawe is not linearly increasing with growth in water demand. When the growth rate of water demand is low, kiawe damage increases slowly 
because damage is only driven by higher future extraction costs. However, at moderate and high growth rates of water demand, the damage cost of kiawe increases drastically due to additional pressure from increased water scarcity and the relatively high cost of the backstop resource (Figure 4a) ${ }^{2}$.

Table 3: Damage cost of kiawe for different rates of uptake, kiawe growth, and water demand (unit: \$)

\begin{tabular}{|c|c|c|c|c|c|c|c|c|}
\hline \multicolumn{2}{|c|}{$\begin{array}{l}\text { Demand growth } \\
\text { Scenario }\end{array}$} & $0 \%$ & $0.5 \%$ & $1 \%$ & $1.5 \%$ & $2 \%$ & $2.5 \%$ & $3 \%$ \\
\hline Baseline & 0.4 & 604 & 800 & 1,105 & 27,955 & 595,603 & $1,051,249$ & $1,447,925$ \\
\hline \multirow{4}{*}{$\begin{array}{c}\text { Sensitivity on } \\
\text { uptake rate }\end{array}$} & 0.8 & 1,210 & 1,602 & 2,214 & 86,493 & $1,201,369$ & $2,114,840$ & $2,908,176$ \\
\cline { 2 - 9 } & 2.4 & 3,650 & 4,836 & 6,694 & 360,591 & $3,742,315$ & $6,472,301$ & $8,843,034$ \\
\cline { 2 - 9 } & 2.8 & 4,263 & 5,651 & 7,825 & 466,726 & $4,406,195$ & $7,587,824$ & $10,353,631$ \\
\hline $\begin{array}{c}\text { Sensitivity on } \\
\text { intrinsic growth } \\
\text { rate }\end{array}$ & $2.5 \%$ & 1,800 & 2,363 & 3,239 & 120,581 & $1,790,793$ & $3,091,941$ & $4,199,587$ \\
\cline { 2 - 9 } & $7.5 \%$ & 2,857 & 3,771 & 5,191 & 210,493 & $2,654,212$ & $4,683,362$ & $6,505,365$ \\
\hline $\begin{array}{c}\text { Sensitivity on } \\
\text { discount rate }\end{array}$ & $0 \%$ & 604 & 711 & 853 & 7,074 & 99,679 & 244,732 & 431,891 \\
\cline { 2 - 9 } & $7 \%$ & 12,585 & 18,659 & 29,271 & $2,370,135$ & $29,081,866$ & $45,275,351$ & $52,702,832$ \\
\hline
\end{tabular}

\footnotetext{
${ }^{2}$ If the time horizon is shorter, water will be less scarce, and kiawe damage costs will be lower than for the 100 -year horizon case presented here. For example, for a 50-year time horizon, with 3\% growth rate of water demand, the damage cost of kiawe is calculated at $\$ 3,999$. The critical growth rate of water demand, where damage cost starts to rise rapidly, is around $7-8 \%$, compared to $1.45 \%$ observed in the 100 -year time horizon case.
} 


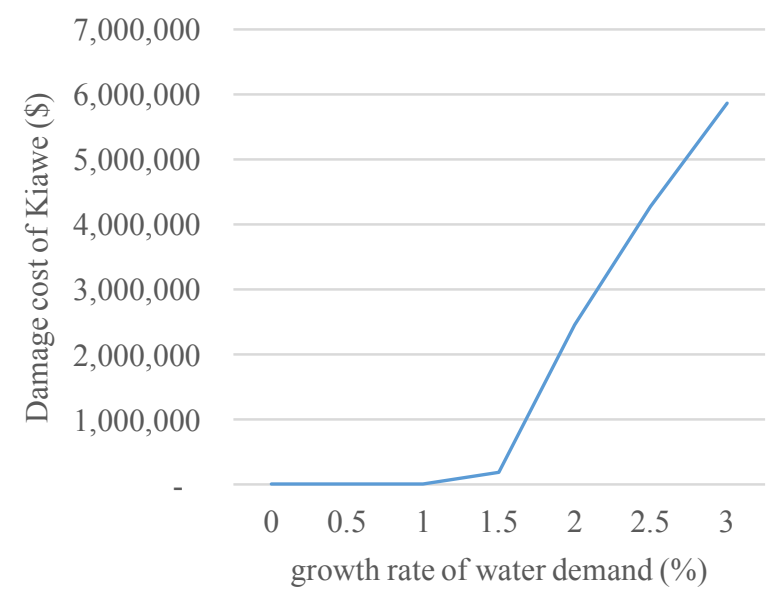

(a) Growth rate of water demand 0-3\%

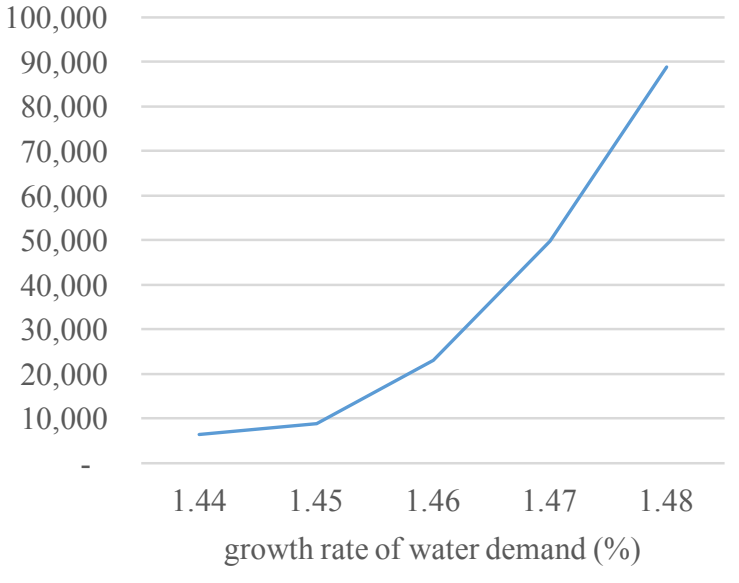

(b) Growth rate of water demand 1.44-1.48\%

\section{Figure 4: Damage cost of kiawe for different water demand growth rates}

The decision of whether to remove kiawe depends primarily on the growth in water demand and kiawe removal costs. For example, when the cost of removal is around $\$ 100 /$ ha, the entire kiawe stock should be removed from the outset if water demand is forecasted to grow faster than $1.45 \%$ per year (Figure $4 \mathrm{~b}$ ). However, if water demand is forecasted to grow more slowly, kiawe should not be removed, as the cost is higher than the benefit of removal. If the estimated cost of removal is doubled to $\$ 200 / \mathrm{ha}$, the critical growth rate of water demand changes only slightly, from 1.45 to $1.46 \%$. And if water demand is forecasted to grow faster than $1.5 \%$, it is very likely that the entire stock of kiawe should be removed in the first period because the critical removal cost is as high as $\$ 1,884 /$ ha.

Management studies in other locations for species similar to kiawe report management costs ranging from as low as $\$ 10 /$ ha up to over $\$ 600 /$ ha in 2016 dollars (March et al., 1996; Teague et al., 1997; Teague et al., 2001; Wise et al., 2012; Shackleton et al., 2015). The differences in costs is driven largely by differences in habitat and removal method. Due to environmental sensitivities and proximity to culturally significant artifacts, in Hawai' $i$ costs for kiawe removal have been estimated to be as high as $\$ 2,800$ per quarter hectare (unpublished data ${ }^{3}$ ). Despite the high estimated cost of kiawe removal in Hawai' $i$, the critical growth rate of water demand remains below $2 \%$. That is, removal of all kiawe in the initial period at a cost of $\$ 24,485 /$ ha is optimal, as long as demand growth is at least $2 \%$.

\subsection{Sensitivity analysis on uptake rate}

The kiawe uptake rate affects water scarcity and hence kiawe damage costs. In the baseline model, an uptake rate of $1.6 \mathrm{tm} / \mathrm{ha} /$ year is applied based on the work done by Miyazawa et al. (2015). We conduct sensitivity analysis for uptake rates equal to $\pm 50 \%$ and $\pm 75 \%$ of the baseline case $\left(0.4,0.8,2.4\right.$ and $2.8 \mathrm{tm}^{3} /$ ha/year). Our results suggest that varying the uptake rate affects

\footnotetext{
${ }^{3}$ Kiawe removal with chain saws and corresponding labor hours was estimated by a private trust managing coastal lands on the island of Hawaii.
} 
the value of kiawe damage. As expected, a higher uptake rate implies higher damage due to increased water scarcity. When water demand is constant, the damage costs of kiawe for the entire area are $\$ 604, \$ 1,210, \$ 2,427, \$ 3,650$, and $\$ 4,263$ for uptake rates of $0.4,0.8,1.6,2.4$, and $2.8 \mathrm{tm}^{3} /$ ha/year respectively (Table 3 ). When water demand is growing at an annual rate of $3 \%$, the damage costs of kiawe for the entire area are $\$ 1.4, \$ 2.9, \$ 5.9, \$ 8.8$ and $\$ 10.4$ million for uptake rates of $0.4,0.8,1.6,2.4$, and $2.8 \mathrm{tm}^{3} /$ ha/year respectively (Table 3 ).

Although the uptake rate affects total kiawe damage substantially, the critical growth rate of water demand, for which damage costs start to increase drastically, is relatively insensitive to uptake values. Figure 5a shows that although the level of damage changes as the uptake rate is varied, the critical growth rates of water demand in all three cases remain clustered around $1.5 \%$. More specifically, a positive or negative change in the baseline uptake rate by $75 \%$ only affects the critical growth rate of water demand by less than $\pm 0.05 \%$ (Figure $5 b$ ). This insensitivity of the critical growth rate suggests that the decision of whether to remove kiawe from the start is not largely dependent on the uptake rate.

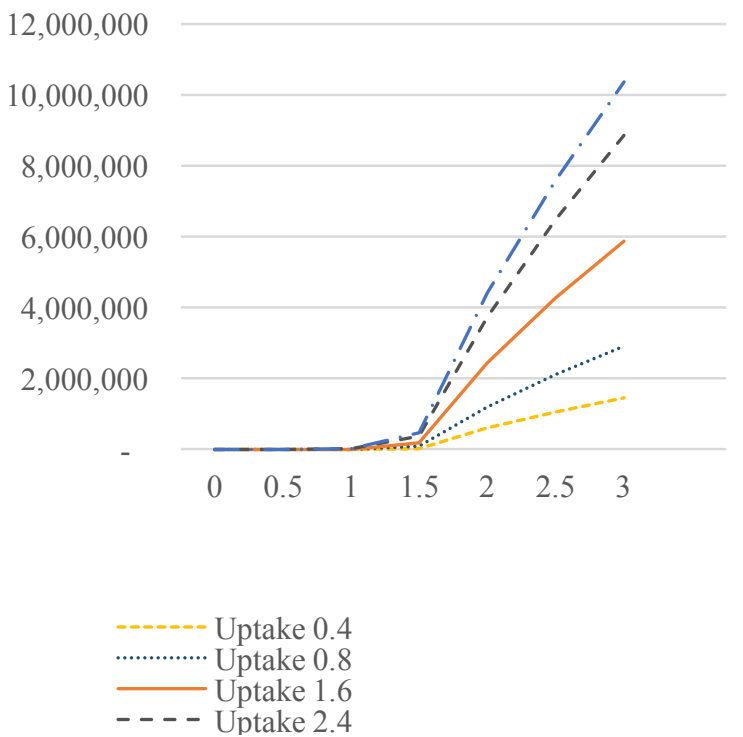

(a) Growth rate of water demand $0-3 \%$

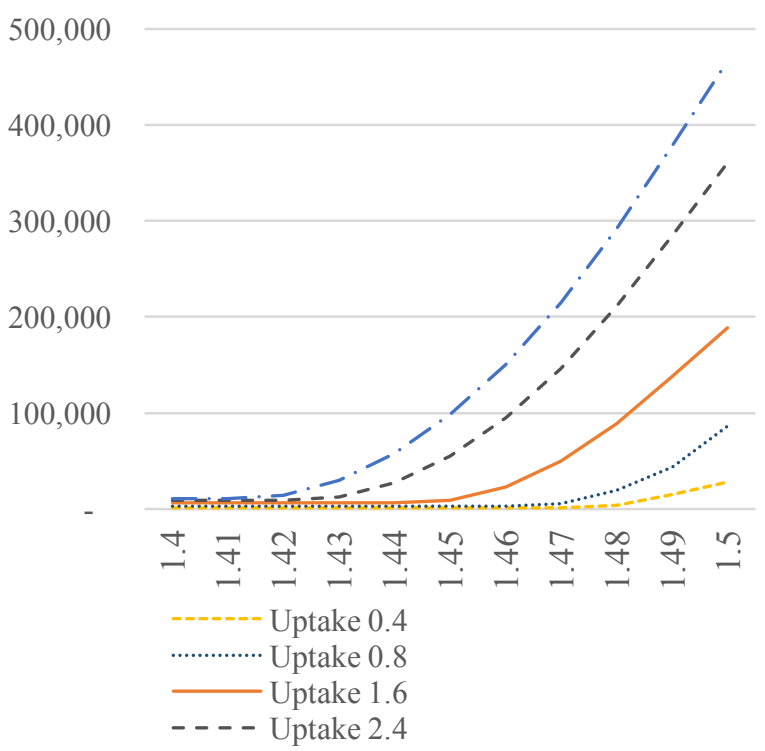

(b) Growth rate of water demand 1.4-1.5\%

Figure 5: Damage cost of kiawe for different uptake rates

\subsection{Sensitivity analysis on intrinsic growth rate of kiawe}

The growth rate of kiawe is an important factor that affects the stock of kiawe and thus, the scarcity of water. For the baseline case, we assume an intrinsic growth rate of $5 \%$. We conduct sensitivity analysis by varying the intrinsic growth rate of kiawe by $\pm 50 \%$ of the baseline case $(2.5 \%$ and $7.5 \%)$. Like for uptake rate, a change in the intrinsic growth rate of kiawe affects the level of damage; the higher the growth rate, the higher the damage cost. For example, when the demand for water is constant, the damage costs of kiawe for the entire area are $\$ 1,800, \$ 2,427$, and $\$ 2,857$ for intrinsic growth rates of $2.5 \%, 5 \%$, and $7.5 \%$ respectively. When the demand for water is growing at $3 \%$ annually, kiawe damage costs for the entire area are $\$ 4.2, \$ 5.9$, and $\$ 6.5$ million for intrinsic growth rates of $2.5 \%, 5 \%$, and $7.5 \%$ respectively (Table 3 ). 
Although an increase in the intrinsic growth rate of kiawe raises the level of damage, it does not affect the critical growth rate of water demand for which damage costs begin to rise drastically. Figure 6 shows that, for intrinsic growth rates within the range of 2.5-7.5\%, the critical growth rate of water demand remains nearly constant, ranging from 1.45-1.48\%. As a result, the decision of whether to remove kiawe from the outset is not sensitive to changes in the intrinsic growth rate. Overall, damage costs and the critical demand growth rate are less sensitive to changes in the intrinsic growth rate than they are to changes in the uptake rate.

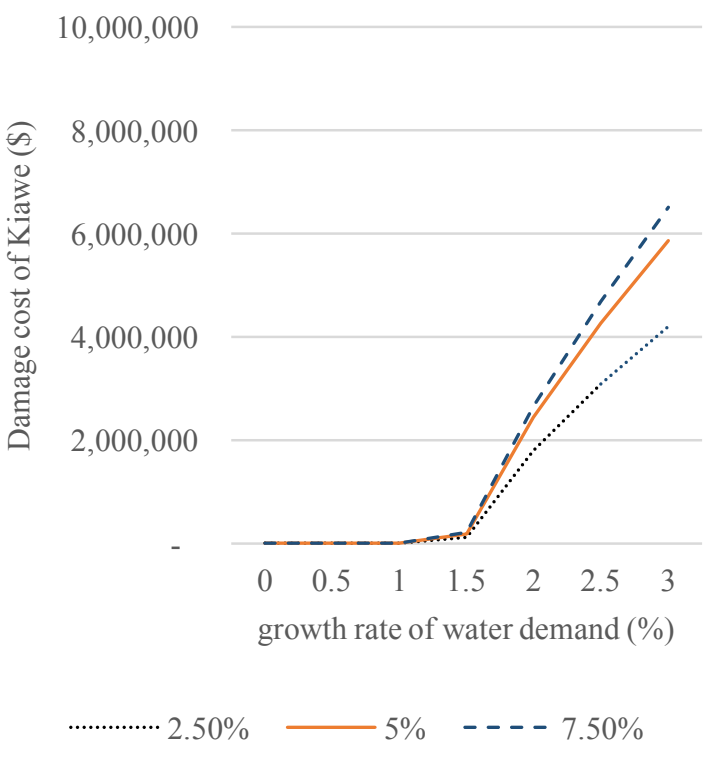

(a) Growth rate of water demand $0-3 \%$

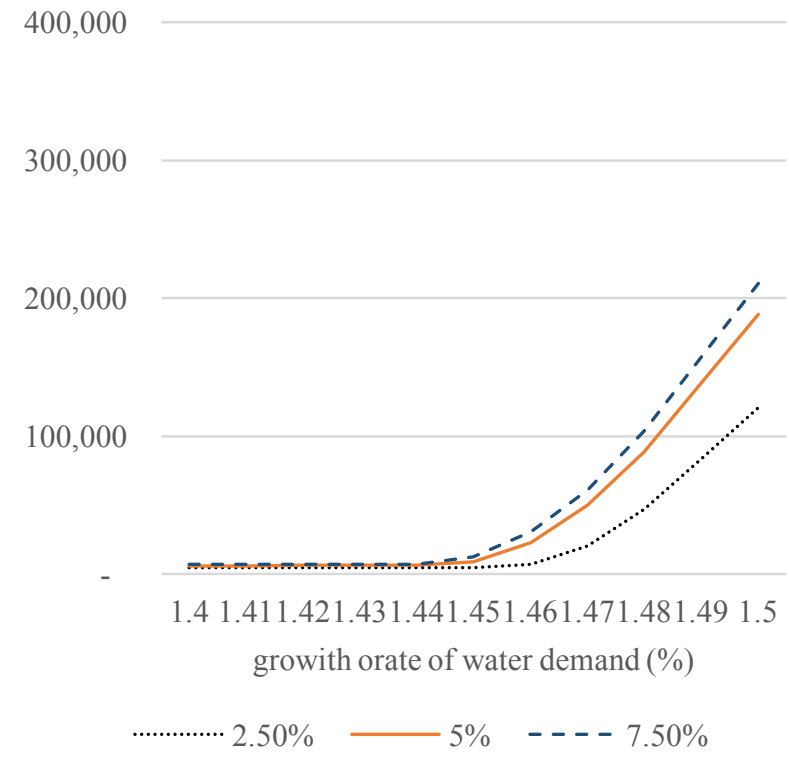

(b) Growth rate of water demand 1.4-1.5\%

\section{Figure 6: Damage cost of kiawe under different kiawe intrinsic growth rates}

\subsection{Sensitivity analysis on discount rate}

The discount rate is another factor affecting costs and consequently optimal planning decisions. It represents how the planner assigns different weights for benefits and costs occurring in different periods. A discount rate of 3\% is applied in the baseline model. In this section, results are calculated for discount rates of $0 \%$ and $7 \%$. We find that, when the discount rate increases, the damage cost of kiawe decreases. For example, when water demand is constant, the damage costs of kiawe for the entire area are $\$ 12,585, \$ 2,427$, and $\$ 604$ for discount rates of $0 \%, 3 \%$, and $7 \%$ respectively (Table 3 ). When water demand is growing at 3\% per year, the damage costs of kiawe for the entire area are $\$ 52.7, \$ 5.9$, and $\$ 0.4$ million for discount rates of $0 \%, 3 \%$, and $7 \%$ respectively (Table 3 ).

The results show that the discount rate affects the damage cost of kiawe substantially. We also find that the critical growth rate of water demand is dependent on the discount rate. In the baseline case with a $3 \%$ discount rate, the critical growth rate of water demand is around $1.45 \%$. 
When the discount rate is $0 \%$, the critical growth rate of water demand drops to around $1 \%$; while for a 7\% discount rate, the critical growth rate increases to around $2 \%$ (Figure 7). The results show that if the discount rate is varied between $0-7 \%$, the critical growth rate of water demand varies between $1-2 \%$. While the results are more sensitive to variations in the discount rate than they are to variations in the rates of kiawe uptake or growth, the absolute change in the critical growth rate of water demand remains small.

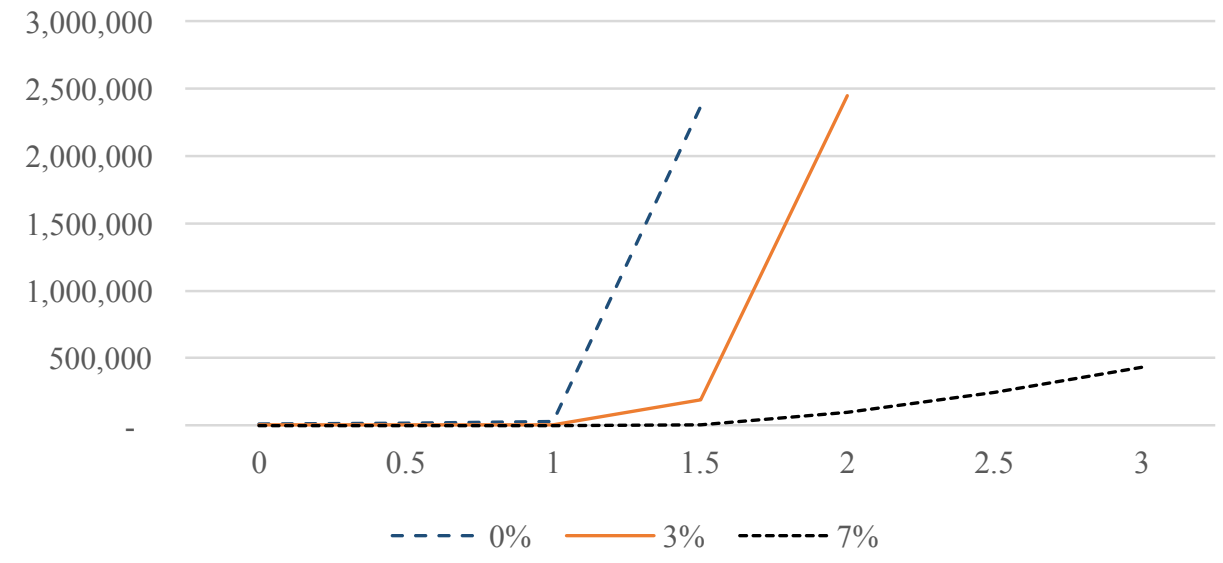

Figure 7: Damage cost of kiawe under different discount rates

\section{Conclusion}

We developed an analytical dynamic framework for the joint optimization of two interacting resources: kiawe and groundwater. The theoretical results suggest that along the optimal path, the efficient extraction of groundwater is partially driven by the effect of kiawe on the groundwater stock. In particular, uptake of groundwater by kiawe reduces future head levels, resulting in higher future extraction costs. At the same time, the optimal path of the kiawe stock, and hence kiawe removal, is driven partially by the shadow price of groundwater. When water is scarcer, the effect of uptake is more pronounced, and the marginal benefit of kiawe removal is higher. Together, these results suggest that managing the resources independently, i.e. treating either of the stocks as exogenous to the model, can result in inefficiency and an overall reduction in welfare.

We then applied our developed framework, using available data for the Kinholo aquifer on the Island of Hawai' $i$. Assuming the unit cost of kiawe removal is constant, the optimal kiawe stock follows a most rapid approach path (MRAP) to its long-run value. Because the MRAP requires a comparison of kiawe marginal (avoided) damage to marginal removal costs, we were interested in simulating the effect of key damage-related parameters. The externality or damage cost of kiawe generally depends on the scarcity of water, so our numerical simulations focused on water scarcity parameters, including water demand growth, the groundwater uptake rate of kiawe, and the intrinsic growth rate of kiawe. We divided optimal outcomes into three categories, based on the growth rate of water demand: zero-to-low, moderate, and high growth rate. In the zero-to-low growth rate category, groundwater is still available at the end of the planning period (year 100), 
and damage costs are driven entirely by higher future groundwater extraction costs. For moderate rates of demand growth, the extraction cost effect on damage is compounded by the need to conserve water toward the end of the planning period. When the growth of demand is high, kiawe damage is further amplified by a backstop effect; higher growth rates result in the implementation of relatively costly desalination to supplement groundwater use before year 100 . Comparing the three scenarios side-by-side, our results suggest that the damage cost of kiawe is not linear in the growth of demand. Damages rise slowly at first but increase substantially once the growth rate exceeds approximately $1.45 \%$. For example, increasing demand growth from $1.45 \%$ to $1.5 \%$ raises the critical damage cost by an order of magnitude from $\$ 88 /$ ha to $\$ 1,884 /$ ha. Given the current range of estimated removal costs, all kiawe should be removed if the growth rate of water demand is at least $2 \%$ per year.

To test the sensitivity of our results to damage-related parameters, we considered a range of kiawe uptake rates, intrinsic growth rates, and discount rates. Even when allowing uptake and kiawe growth to vary by $\pm 75 \%$ and $\pm 50 \%$ of the baseline values respectively, the general outcomes remain largely unchanged. The overall level of kiawe damage shifts up, but the critical demand growth rate remains close to $1.45 \%$. Given the assumptions of our model, the decision of if/when to optimally remove kiawe is much more sensitive to the rate of water demand growth than it is to both the intrinsic growth rate of kiawe and the rate of groundwater uptake by kiawe. Varying the discount rate has a relatively large effect on the damage cost of kiawe and the critical demand growth rate, which is not unexpected given the length of the time horizon (100 years) under consideration.

We conclude with a brief discussion of potential extensions to the developed framework and directions for further research. Although we tested the sensitivity of our results by varying several of the parameter values, uncertainty was not built directly into the model. The robustness of our results could be improved by integrating methods developed by others to address stochastic water demand problems (e.g. Koundouri, 2004; Korteling et al., 2013; Matrosov et al., 2013; Beh et al., 2015), especially as the weather becomes more extreme and unpredictable in Hawai'i (Elison Timm et al., 2015; Zhang et al. 2016) and elsewhere. A more sophisticated approach to modeling the biology of kiawe could also change our management implications. The optimal removal of kiawe in our model followed a most rapid approach path by design. Generally, however, the optimal control strategy could be age/size dependent if, for example, root depth is modeled to increase with age. Furthermore, if a constraint on maximum root depth could be reasonably approximated - current studies suggest that the value ranges across Prosopis species and locations from 2 to 53 meters (Stone and Kalisz, 1991; Canadell et al., 1996; Le

Matire et al., 1998) — there may be an incentive to deplete the aquifer sooner rather than later to reduce uptake.

\section{Acknowledgements}

This research was funded in part by a travel grant from Chulalongkorn University, Thailand, and National Science Foundation EPSCoR Grant No. EPS-0903833. We are grateful to Flint Hughes (Institute of Pacific Islands Forestry, USDA-Forest Service), Bruce Dudley (New Zealand National Institute of Water and Atmospheric Research), and Mana Purdy (Queen Lili'uokalani Trust) for providing data, insight and/or expertise. However, any remaining errors are our own. 


\section{References}

Barbier, E.B., Strand, I., Sathirathai, S., 2002. Do open access conditions affect the valuation of an externality? Estimating the welfare effects of mangrove-fishery linkages in Thailand. Environ. Resour. Econ. 21, 343367.

Beh, E.H.Y., Dandy, G.C., Maier, H.R., Paton, F.L., 2014. Optimal sequencing of water supply options at the regional scale incorporating alternative water supply sources and multiple objectives. Environmental Modelling \& Software 53, 137-153.

Beh, E.H.Y., Maier, H.R., Dandy, G.C., 2015. Adaptive, multiobjective optimal sequencing approach for urban water supply augmentation under deep uncertainty. Water Resources Research 51(3), 1529-1551.

Birkett, M. E. 2007. Forging French foreign policy in the Pacific. Fr. Colonial Hist. 8:155-169.

Brown, G., Deacon, R., 1972. Economic optimization of a single cell aquifer. Water Resour. Res. 8,552564 .

Brozović, N., Sunding, D.L., Zilberman, D., 2010. On the spatial nature of the groundwater pumping externality. Resour. Energy Econ. 32, 154164.

Burnett, K., B. Kaiser and J. Roumasset. 2007. Economic Lessons from Control Efforts for an Invasive Species: Miconia calvescens in Hawaii, Journal of Forest Economics 13 (2-3): 151-167.

Burnett, K. M., Roumasset, J. A., Wada, C. A. 2014. Optimal Joint Management of Interdependent Resources: Groundwater Versus Kiawe (Prosopis pallida). In: Arsenio M. Balisacan, Ujjayant Chakravorty and Majah-Leah V. Ravago, editors, Sustainable Economic Development. Oxford: Academic Press, pp. 91-104.

Burt, O.R., 1967. Temporal allocation of groundwater. Water Resour. Res. 3, 4556.

Canadell, J., Jackson, R.B., Ehleringer, J.B., Mooney, H.A., Sala, O.E., Schulze, E.-D., 1996. Maximum rooting depth of vegetation types at the global scale. Oecologia 108(4), 583595.

Chiang, A.C. 2000. Elements of Dynamic Optimization. Waveland Press, Inc., Long Grove, Illinois.

Connelly, N.A., C.R., O’Neill Jr., Knuth, B.A., Brown, T.L. 2007. Economic Impacts of Zebra Mussels on Drinking WaterTreatment and Electric Power Generation Facilities. Environmental Management, 40:105-112. 
Conrad, J.M. 2012. Resource Economics, $2^{\text {nd }}$ Edition. Cambridge University Press, New York.

Duarte, T.K. 2002. Long-term management and discounting of groundwater resources with a case study of Kuki'o, Hawai'i. Ph.D. dissertation. Department of Civil and Environmental Engineering, Massachusetts Institute of Technology.

Duarte, T.K., Pongkijvorasin, S., Roumasset, J., Amato, D., Burnett, K., 2010. Optimal management of a Hawaiian coastal aquifer with nearshore marine ecological interactions. Water Resour. Res. 46, W11545;

Dudley BD, Hughes RF, Ostertag R. 2014. Groundwater availability mediates the ecosystem effects of an invasion of Prosopis pallida. Ecological Applications 24: 1954-1971.

Dzikiti, S., Schachtschneider, K., Naiken, V., Gush, M., Moses, G., Le Maitre, D.C., 2013. Water relations and the effects of clearing invasive Prosopis trees on groundwater in an arid environment in the Norther Cape, South Africa. Journal of Arid Environments 90: 103-113.

Elison Timm, O., Giambelluca, T.W., Diaz, H.F., 2015. Statistical downscaling of rainfall changes in Hawai' $i$ based on the CMIP5 global model projections. J. Geophys. Res. Atmos. 120(1), 92-112.

Funk, J.L V. Matzek, M. Bernhardt, D. Johnson. 2014. Broadening the Case for Invasive Species Management to Include Impacts on Ecosystem Services, BioScience, Volume 64, Issue 1, 1 January 2014, Pages 58-63

Gerlach JDJr. The impacts of serial land-use changes and biological invasions on soil water resources in California, USA., Journal of Arid Environments, 2004, vol. 57 (pg. 365-379)

Gon, S. M., A. Allison, R. J. Cannarella, J. D. Jacobi, K. Y. Kaneshiro, M. H. Kido, M. LaneKamahele, and D. S. E. Miller. 2006. A GAP analysis of Hawaii: Final report. U.S. Department of the Interior, U.S. Geological Survey, Washington, D.C.

Hall, W. L. 1904. The forests of the Hawaiian Islands. Bureau of Forestry, U.S. Department of Agriculture, Washington, D.C.

Jones B.A., McDermott S.M., Chermak J.M. 2006. PLAN or get SLAM'ed: Optimal management of invasive species in the presence of indirect health externalities. Journal of Environmental Management, 180: 538-50.

Korteling, B., Dessai, S., Kapelan, Z., 2013. Using Information-Gap Decision Theory for Water Resources Planning Under Severe Uncertainty. Water Resources Management, 27(4), 1149-1172.

Koundouri, P. 2004, Current Issues in the Economics of Groundwater Resource Management. 
Journal of Economic Surveys, 18: 703-740. doi:10.1111/j.1467-6419.2004.00234.x

Krulce, D.L., Roumasset, J.A., Wilson, T., 1997. Optimal management of a renewable and replaceable resource: the case of coastal groundwater. Am. J. Agric. Econ. 79, 1218 1228.

Le Maitre, D.C., Gush, M.B., Dzikiti, S., 2015. Impacts of invading alien plant species on water flows at stand and catchment scales. AOB Plants 7: plv043.

Le Maitre, D.C., Scott, D.F., Colvin, C., 1998. A review of information on interactions between vegetation and groundwater. Water SA 25(2), 137-152.

March, N., Akers, D., Jeffrey, P., Vitelli, J., Mitchell, T., James, P., Mackey, A.P., 1996. Mesquite (Prosopis spp.) in Queensland. Pest Status Review Series - Land Protection Branch, Queensland Government, Natural Resources and Mines.

Matrosov, E.S., Padula, S., Harou, J.J., 2013. Selecting Portfolios of Water Supply and Demand Management Strategies Under Uncertainty - Contrasting Economic Optimisation and 'Robust Decision Making' Approaches. Water Resources Management 27(4): 1123-1148.

Mink, J.F., 1980. State of the Groundwater Resources of Southern Oahu. Board of Water Supply, Honolulu.

Miyazawa, Y., Dudley, B.D., Hughes, R.F., Vandermark, J., Cordell, S., Nullet, M.A., Ostertag, R., and Giambelluca, T.W. 2016. Non-native tree in a dry coastal area in Hawai'i has high transpiration but restricts water use despite phyreatophytic trait. Ecohydrology, doi: 10.1002/eco.1715.

Pasiecznik, N. M., P. Felker, P. J. C. Harris, L. N. Harsh, G. Cruz, J. C. Tewari, K. Cadoret, and L. J. Maldonado. 2001. The Prosopis juliflora-Prosopis pallida complex: A monograph. Henry Doubleday Research Association, Coventry, United Kingdom.

Peterson RN, Burnett WC, Glenn CR, Johnson AG. 2009. Quantification of point-source groundwater discharges to the ocean from the shoreline of the Big Island, Hawaii. Limnology and Oceanography 54: 890-904.

Pongkijvorasin, S., Roumasset, J., Duarte, T.K., Burnett, K. 2010. Renewable resource management with stock externalities: Coastal aquifers and submarine groundwater discharge. Resource and Energy Economics 32: 277-291.

Richmond, T.d.A., Mueller-Dombois, D., 1972. Coastline ecosystems on Oahu, Hawaii. Plant Ecol. 25, 367400 .

Roumasset, J.A., Wada, C.A., 2010. Optimal and Sustainable Groundwater Extraction. Sustainability 2(8), 2676-2685. 
Saif, Y., Almansoori, A., 2014. Design and operation of water desalination supply chain using mathematical modelling approach. Desalination 351, 184-201.

Schade, J. D., R. Sponseller, S. L. Collins, and A. Stiles. 2003. The influence of Prosopis canopies on understory vegetation: Effects of landscape position. J. Veg. Sci. 14:743750.

Shackleton, R.T., Le Maitre, D.C., Richardson, D.M., 2015. Stakeholder perceptions and practices regarding Prosopis (mesquite) invasions and management in South Africa. Ambio 44: 569-581.

Stearns, H. T. 1940. Geology and ground- water resources of the islands of Lanai and Kahoolawe, Hawaii. Bulletin of the Division of Hydrography, Territory of Hawaii \#6 Honolulu.

Stone, E.L., Kalisz, P.J., 1991. On the maximum extent of tree roots. Forest Ecology and Management 46, 59-102.

Teague, R., Borchardt, R., Ansley, J., Pinchak, B., Cox, J., Foy, J.K., McGrann, J., 1997. Sustainable Management Strategies for Mesquite Rangeland: The Waggoner Kite Project. Rangelands 19(5): 4-8.

Teague, W.R., Ansley, R.J., Kreuter, U.P., Pinchak, W.E., McGrann, J.M., 2001. Economics of Managing Mesquite in North Texas: A Sensitivity Analysis. Journal of Range Management 54(5): 553-560.

Turpie JK, Marais C, Blignaut JN. 2008. The working for water programme: Evolution of a payments for ecosystem services mechanism that addresses both poverty and ecosystem service delivery in South Africa., Ecological Economics. 65: 788-798.

Van Wilgen BW, Khan A, Marais C. Richardson DM. 2011. Changing perspectives on managing biological invasions: Insights from South Africa and the working for water programme, Fifty Years of Invasion Ecology: The Legacy of Charles Elton. WileyBlackwell, 377-393.

Wada, C., L. Bremer, K. Burnett, C. Trauernicht, T. Giambelluca, L. Mandle, E. Parsons, C. Weil, N. Kurashima, T. Ticktin. 2017. Estimating the Cost-Effectiveness of Hawaiian Dry Forest Restoration Using Spatial Changes in Water Yield and Landscape Flammability under Climate Change. Pacific Science 71(4), in press.

Wilcox, E. V. 1910. The algaroba in Hawaii. Hawaii Agric. Exp. Stn. Press Bull. 26:1-8.

Wise, R.M., van Wilgen, B.W., Le Maitre, D.C., 2012. Costs, benefits and management options for an invasive alien tree species: The case of mesquite in the Northern Cape, South Africa. Journal of Arid Environments 84: 80-90. 
Zavaleta E. 2000. The economic value of controlling an invasive shrub. AMBIO. 29: 462-467.

Zhang, C., Wang, Y., Hamilton, K., Lauer, A., 2016. Dynamical Downscaling of the Climate for the Hawaiian Islands. Part II: Projection for the Late Twenty-First Century. J. Climate 29, 8333-8354.

Zones, C. P. 1961. Discharge of ground water by phreatophytes in the Waianae district, Oahu Hawaii. U.S. Department of the Interior, U.S. Geological Survey, Washington, D.C. 